\title{
Two Cases of Intracranial Aneurysm Case Treated with Coil Embolization Using the T-stenting Technique
}

Tomoyoshi Kuribara, Koichi Haraguchi, Takehiro Saga, Tadakazu Shimizu, Nobuki Matsuura,

Kazumi Ogane, and Takeo Itou

Objective: We report two cases of unruptured intracranial aneurysms treated with the coil embolization using T-stenting technique.

Case Presentations: Case 1 was a 49-year-old woman with wide-neck basilar tip aneurysm $(10.8 \mathrm{~mm} \times 9.8 \mathrm{~mm} \times 8.9 \mathrm{~mm})$ riding on the origin of the bilateral posterior cerebral arteries. Case 2 was an 84 -year-old woman with left internal carotid artery-posterior communicating artery aneurysm $(16.8 \mathrm{~mm} \times 13.5 \mathrm{~mm} \times 12.6 \mathrm{~mm})$ and the ipsilateral posterior communicating artery (Pcom) was branched from the dome of the aneurysm. Both cases were treated with coil embolization using the T-stenting technique without any neurological deficits.

Conclusion: Although the T-stenting technique is accompanied by a difficulty on the occasion of stent placement in comparison with the Y-stenting technique, such a technique has a potential benefit to reduce the risk of thrombotic complications.

Keywords $>$ T-stenting technique, nonoverlapping Y-configuration stenting technique, cerebral aneurysm, coil embolization

\section{Introduction}

In coil embolization performed with the stent assist technique, the incidence of thrombotic complications has been reported to be $4.4 \%-5.4 \%$ even by simple stenting. ${ }^{1,2)}$ In patients who require a complicated stenting technique, such as dual stenting, there is concern over a further increase in thrombotic complications. T-stenting, which is one of the dual stenting techniques, was devised to reduce thrombotic complications by avoiding crossing of stents and was reported as a "nonoverlapping Y-configuration stenting technique."3) However, it is performed infrequently because of the difficulty of the procedure. In this report, two cases treated by intra-aneurysmal coil embolization using the T-stenting technique are presented.

Department of Neurosurgery, Hakodate Shintoshi Hospital, Hakodate, Hokkaido, Japan

Received: December 7, 2015; Accepted: May 31, 2016

Corresponding author: Tomoyoshi Kuribara. Department of Neurosurgery, Hakodate Shintoshi Hospital, 331-1 Ishikawacho, Hakodate, Hokkaido 041-0802, Japan

Email: kuribara@yushinkai.jp

(C)2016 The Editorial Committee of Journal of Neuroendovascular Therapy. All rights reserved.

\section{Case Presentation}

\section{Case 1}

The patient was a 49-year-old woman who had a history of cerebrovascular dementia, chronic heart failure, old myocardial infarction, and ischemic mitral insufficiency and was orally administered aspirin at $81 \mathrm{mg} /$ day.

She consulted the neurosurgery department of a local hospital due to headache and abnormal sensation of the bilateral fingers. Since a head CT scan suggested the presence of an aneurysm at the basilar tip, she was referred to our hospital.

On admission, the consciousness was clear, and no neurological abnormality was noted. Neuroradiologically, head CT/ CTA showed a wide-neck aneurysm with a size of $10.8 \mathrm{~mm} \times$ $9.8 \mathrm{~mm} \times 8.9 \mathrm{~mm}$ at the basilar tip riding over the bilateral posterior cerebral arteries (PCA) (Figs. 1A and 1B).

\section{Treatment plan}

Since the patient was relatively young, and since the risk of complications, such as damaging the perforating branches, was high by craniotomy and clipping, coil embolization was selected. The T-stenting technique was employed to preserve the bilateral PCAs and prevent thrombotic complications. The administration of clopidogrel at $75 \mathrm{mg} /$ day and cilostazol at $100 \mathrm{mg} /$ day was added since 5 days before surgery. 

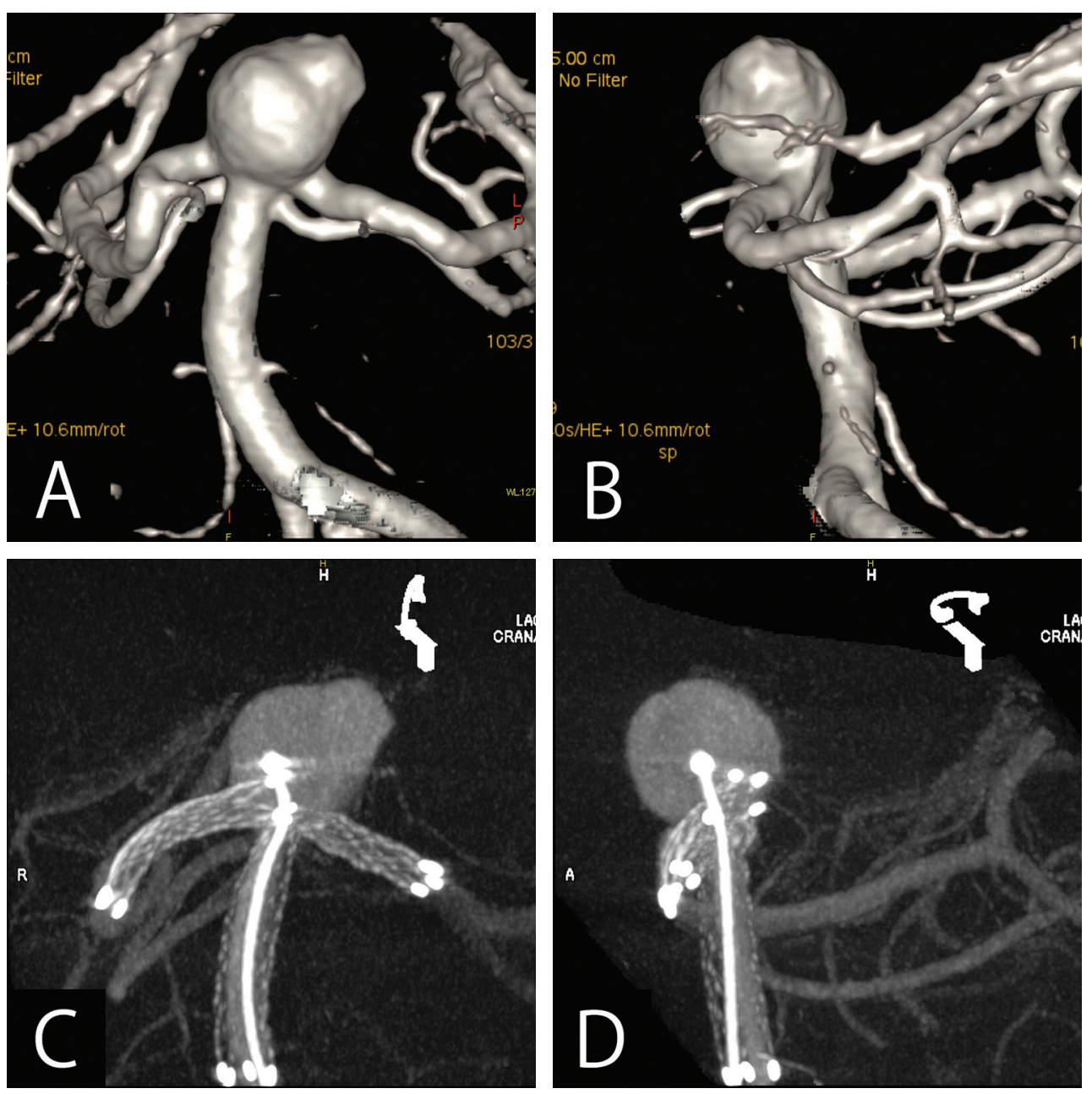

Fig. 1 (A, B) 3D-CTA shows the wide-neck basilar artery tip (BA tip) aneurysm that rides on origins of the bilateral posterior cerebral artery (PCA). (C, D) Cone beam CT shows deployed stents cover the neck of the BA tip aneurysm precisely and preserve the origins of the bilateral PCA.

\section{Endovascular procedure}

Launcher 5Fr $90 \mathrm{~cm}$ (Medtronic, Minneapolis, MN, USA) was placed in the right vertebral artery (VA), and FUBUKI 6Fr $90 \mathrm{~cm}$ (Asahi Intecc, Aichi) was placed in the left VA, via the bilateral femoral arteries. Prowler select plus $45^{\circ}$ (Codman \& Shurtleff, Johnson \& Johnson, Raynham, MA, USA) was guided to the left PCA, and Headway 17 Advanced $45^{\circ}$ (MicroVention, TERUMO, Tustin, CA, USA) was guided into the aneurysm. First, EnterpriseVRD $4.5 \mathrm{~mm} \times 28 \mathrm{~mm}$ NO TIP (Codman \& Shurtleff, Johnson \& Johnson, Raynham, MA, USA) was placed in the basilar artery via the left PCA. Then, Prowler select plus $45^{\circ}$ was guided to the right PCA by the trans-cell technique, and EnterpriseVRD $4.5 \mathrm{~mm} \times 14 \mathrm{~mm}$ NO TIP was inserted. In consideration of shortening, it was deployed from a position at which the proximal marker slightly overlapped with the first stent in the left PCA and placed by barely avoiding overlapping with the first EnterpriseVRD. The state of placement of the stents was confirmed to be appropriate by cone beam CT (Figs. 1C and 1D). After framing with Axium 3D $10 \mathrm{~mm} \times 30 \mathrm{~mm}$ (eV3 Covidien, Irvine, CA, USA), the aneurysm was embolized with a total of 16 coils including Axium, VFC (MicroVention, TERUMO, Tusin, CA, USA), ED coil (Kaneka Medics, Osaka), and Target (Stryker, Kalamazoo, MI, USA) with a total length of $180 \mathrm{~cm}$, and the procedure was ended in a state of body filling (Figs. 2A and 2B).

The post-procedural course was free of clear complications. While follow-up cerebral angiography after 6 months showed slight coil compaction in a posterior part of the aneurysm, the patient continues to be followed up on an outpatient basis (Figs. 2C and 2D). 

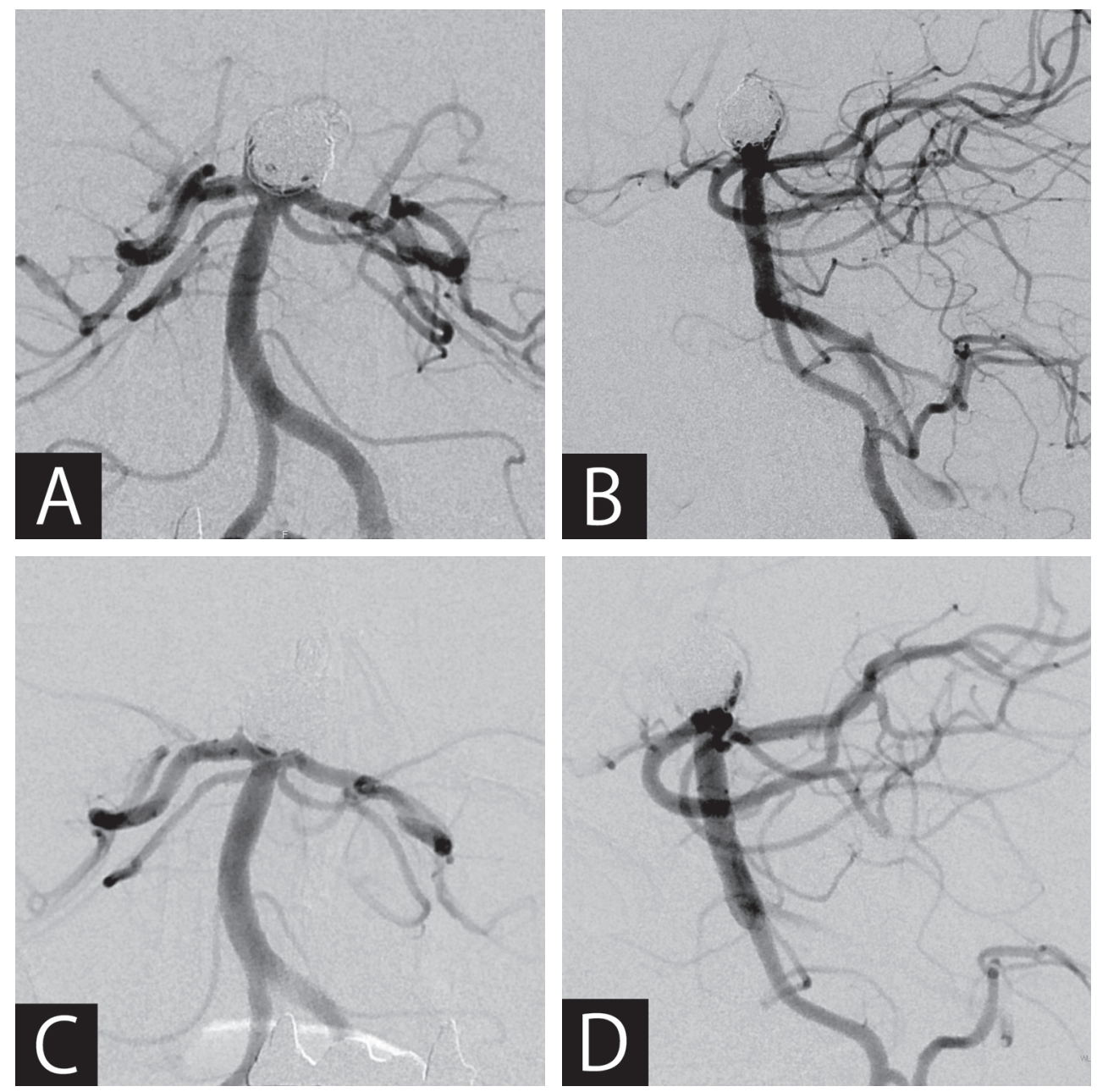

Fig. 2 (A, B) Working angle view after the embolization. (C, D) Working angle view 6 months after the embolization. Angiography of the left vertebral artery (VA) after the embolization reveals body filling. Left VA angiography 6 months after the embolization shows minor recanalization at the posterior side of the BA tip aneurysm. BA: basilar artery

\section{Case 2}

The patient was an 84-year-old woman who had a history of lumbar spinal canal stenosis and sudden-onset deafness and was orally treated with aspirin at $100 \mathrm{mg} /$ day.

The patient was known to have an aneurysm at the right internal carotid artery-posterior communicating artery (ICPC) bifurcation and was followed up as an outpatient at our hospital. Since the aneurysm clearly enlarged and changed in shape, it was decided to treat it.

On admission, the consciousness was clear, and no neurological abnormality was noted. Neuroradiologically, a right IC-PC aneurysm measuring $16.8 \mathrm{~mm} \times 13.5 \mathrm{~mm} \times 12.6 \mathrm{~mm}$ with the posterior communicating artery (Pcom) originating from the dome was observed by 3D-DSA (Figs. 3A and 3B). On the balloon occlusion test, disturbance of consciousness was immediately induced, and the absence of ischemic tolerance was confirmed. The patient had underdeveloped anterior communicating artery (Acom) and a fetal type right Pcom.

\section{Treatment plan}

Considering the large diameter of the aneurysm and old age of the patient, the risk of craniotomy and clipping was judged to be high. Also, because of the absence of ischemic tolerance, coil embolization with preservation of the parent artery was selected. Since preservation of the fetal type right Pcom was essential, the T-stenting technique was employed for its preservation and prevention of thrombotic complications. The administration of clopidogrel at $50 \mathrm{mg} /$ day and cilostazol at $100 \mathrm{mg} /$ day was added from 5 days before the procedure.

\section{Endovascular procedure}

FUBUKI $8 \mathrm{Fr} 90 \mathrm{~cm}$ was placed in the right internal carotid artery (ICA) via the right femoral artery. Two Prowler select 

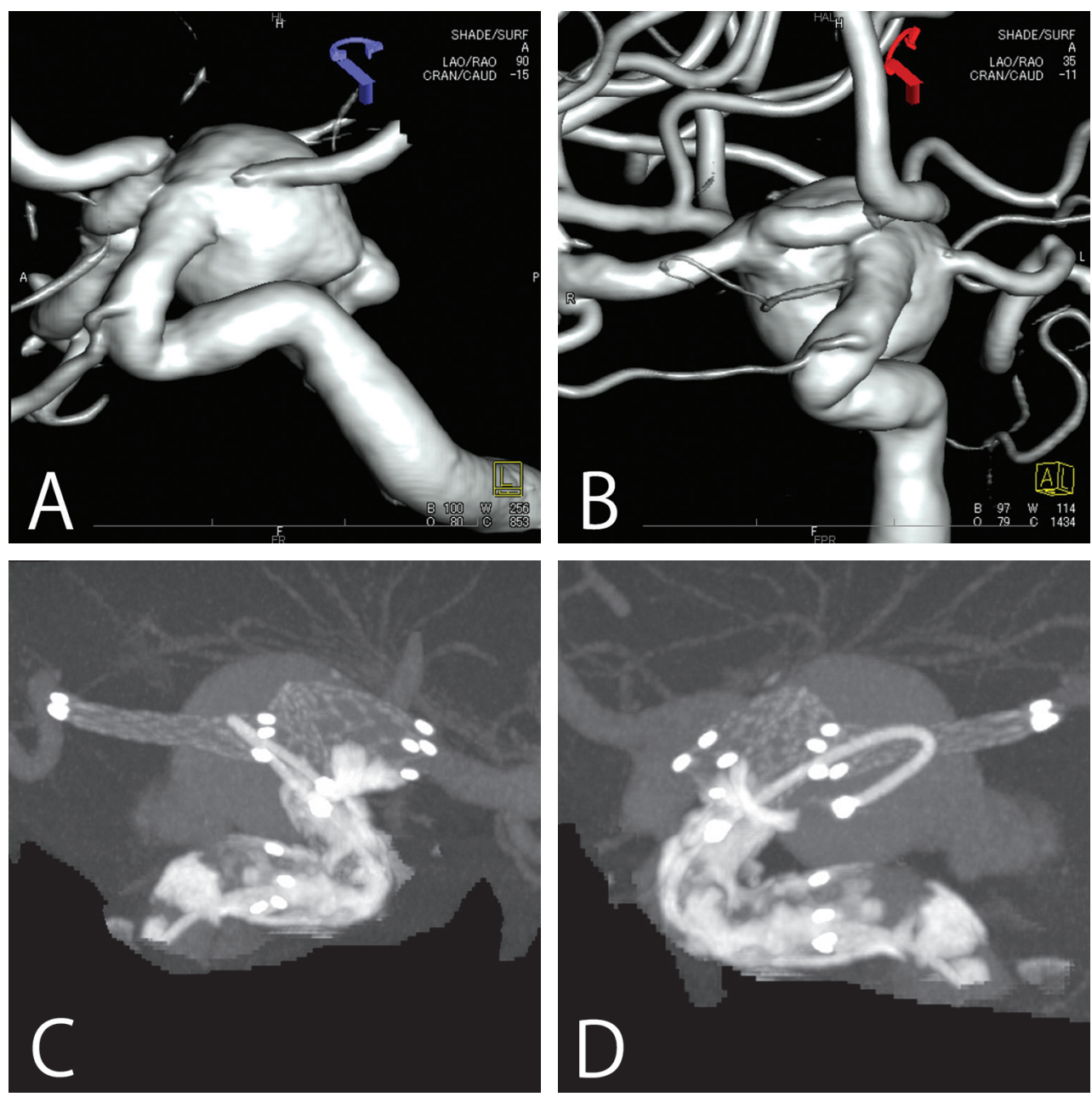

Fig. 3 (A, B) 3D-DSA shows the wide-neck internal carotid artery-posterior communicating artery (IC-PC) aneurysm. The origin of the posterior communicating artery (Pcom) is branched from the dome of the aneurysm. (C, D) Cone beam CT shows deployed stents cover the neck of the IC-PC aneurysm precisely and preserve the ipsilateral internal carotid artery (ICA) and Pcom.

plus $45^{\circ}$ were guided to a distal part of the right ICA and right Pcom, and Headway 17 Advanced J was guided into the aneurysm. First, EnterpriseVRD $4.5 \mathrm{~mm} \times 37 \mathrm{~mm}$ NO TIP was placed in the right ICA. Next, in consideration of shortening, it was deployed from a position at which the proximal marker slightly overlapped with the first stent in the right ICA, and EnterpriseVRD $4.5 \mathrm{~mm} \times 14 \mathrm{~mm}$ NO TIP was placed in the right Pcom by barely avoiding overlapping of the stents. The state of stent placement was confirmed to be appropriate by cone beam CT (Figs. 3C and 3D). After framing with Target XL-360 STANDARD $12 \mathrm{~mm} \times 45 \mathrm{~mm}$, the aneurysm was embolized using 8 DELTAMAXX 18 CERECYTE (Codman \& Shurtleff, Johnson \& Johnson, Raynham, MA, USA) coils with a total length of $237 \mathrm{~cm}$, and the procedure was ended in a state of body filling (Figs. 4A and 4B).
The post-procedural course was free of clear complications, and no marked change was noted by head MRI/A after 3 months (Figs. 4C and 4D).

\section{Discussion}

In most stent assist techniques, simple stenting using one stent is employed. However, the dual stenting technique using two stents is indicated when the preservation of branched arteries is difficult, when the neck of the aneurysm is difficult to identify, requiring the preparation of a neck, and when the recurrence is likely due to a large size of the aneurysm. ${ }^{4}$ ) Among the dual stenting techniques, the Y-stenting technique, which is also called the overlapping Y-configuration stenting technique, is employed relatively frequently. There are two major 

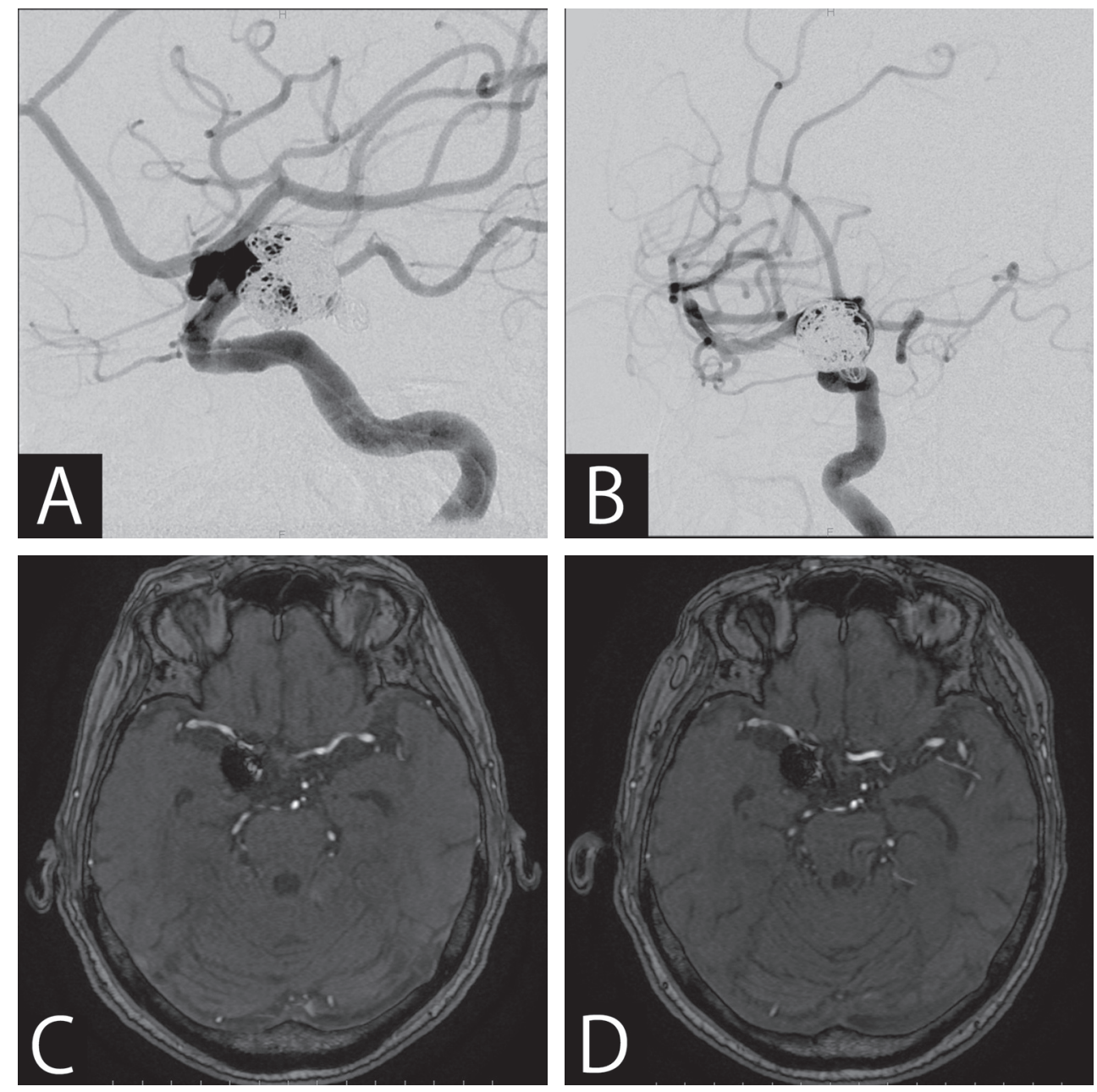

Fig. 4 (A, B) working angle view. (C) MRA on the day after the embolization. (D) MRA 3 months after the embolization. Right ICA angiography after the embolization reveals body filling. There seems to be no recanalization 3 months after the embolization. ICA: internal carotid artery

variations in the Y-stenting technique: Crossing Y, in which the first stent is placed in one branched artery, then other branched artery is selected by the trans-cell technique, and the second stent is deployed from this vessel; ${ }^{5}$ ) and Kissing Y, in which two stents are placed parallel with the parent artery from the two branched arteries. ${ }^{\text {) }}$ On the other hand, the T-stenting technique described in this report, also called the nonoverlapping Y-configuration stenting technique, was devised to control thrombus formation and stent malapposition due to narrowing of the stent by avoiding stent crossing and, thus, reduce thrombotic complications. Table 1 summarizes the reports of five or more cases treated by the T-stenting or Y-stenting technique.,3,7-12) When these techniques were used, the incidence of ischemic complications was 4.4\%.,3,7-12) By the site, the incidence was $5.6 \%$ in the middle cerebral artery (MCA), $11.4 \%$ in the Acom, $3.5 \%$ in the BA-tip, $0 \%$ in the IC tip, and $0 \%$ in the IC-PC., ${ }^{3,-12)}$ The T-stenting technique was performed in seven patients, ${ }^{3,4)}$ and while the presence or absence of complications was unknown in one, no clear ischemic complication was noted in six. Because of the small size of the series, it is impossible to discuss whether or not the T-stenting technique reduces thrombotic complications, and further accumulation of cases is necessary. While the incidence of ischemic complications of $4.4 \%$ was satisfactory when compared with the results of simple stenting, ${ }^{1,2)}$ Johnson et al. reported that the Y-stenting technique significantly increased the incidence of ischemic and hemorrhagic complications compared with simple stenting. ${ }^{13)}$ The report mentioned friction against the vascular wall associated with interference between stents as a cause of the increase in complications and suggested the usefulness of the T-stenting technique. Also, according to the results by the site of aneurysm, 
Table 1 Summary of previous studies including more than five cases that T-stenting technique or Y-stenting technique were performed ${ }^{1,2,3,4,7-12)}$

\begin{tabular}{|c|c|c|c|c|}
\hline Author & $\begin{array}{l}\text { Number } \\
\text { legion }\end{array}$ & $\begin{array}{l}\text { Attempted } \\
\text { stenting }\end{array}$ & Technique & $\begin{array}{c}\text { Ischemic } \\
\text { complication }\end{array}$ \\
\hline Thorell W, et al. (2005) & BA-tip 7 (100\%) & $1(14.3 \%)$ & Y & BA-tip $2(28.6 \%)$ \\
\hline \multicolumn{5}{|l|}{$\mathrm{N}=7$} \\
\hline Lozen A, et al. (2009) & MCA 1 (16.7\%) & $0(0 \%)$ & $\mathrm{Y}$ & $0(0 \%)$ \\
\hline$N=6$ & BA-tip 5 (83.3\%) & & & \\
\hline Cho YD, et al. (2012) & BA-tip 6 (100\%) & $0(0 \%)$ & $\mathrm{T}$ & $0(0 \%)$ \\
\hline \multicolumn{5}{|l|}{$N=6$} \\
\hline Lee WJ, et al. (2012) & MCA 3 (25\%) & $0(0 \%)$ & $\mathrm{Y}$ & $0(0 \%)$ \\
\hline$N=12$ & BA-tip 9 (75\%) & & & \\
\hline Zhao KJ, et al. (2012) & MCA $3(27.3 \%)$ & $0(0 \%)$ & $\mathrm{Y}$ & Acom $1(9.1 \%)$ \\
\hline \multirow[t]{3}{*}{$\mathrm{N}=11$} & Acom 2 (18.2\%) & & & \\
\hline & BA-tip 5 (45.5\%) & & & \\
\hline & IC-PC 1 (9.1\%) & & & \\
\hline Yavuz K, et al. (2013) & MCA113 (58.5\%) & $3(1.6 \%)$ & Y192 (99.5\%) & Total 5 (2.6\%) \\
\hline \multirow[t]{3}{*}{$N=193$} & Acom 42 (21.8\%) & & T1 (0.5\%) & \\
\hline & BA-tip 22 (11.4\%) & & & \\
\hline & IC-tip $16(8.3 \%)$ & & & \\
\hline Akqul E, et al. (2015) & MCA 7 (35\%) & $0(0 \%)$ & $\mathrm{Y}$ & $0(0 \%)$ \\
\hline \multirow[t]{3}{*}{$N=20$} & Acom 3 (15\%) & & & \\
\hline & BA-tip 9 (45\%) & & & \\
\hline & ACA1 (5\%) & & & \\
\hline Bartolini B, et al. (2015)* & MCA 57 (54.3\%) & $11(10.5 \%)$ & Y & MCA 4, \\
\hline \multirow[t]{3}{*}{$N=105$} & Acom 30 (28.6\%) & & & Acom 4 \\
\hline & BA-tip 17 (16.2\%) & & & Total $8(7.6 \%)$ \\
\hline & IC-tip 1 (1\%) & & & \\
\hline \multirow[t]{6}{*}{ Total $\mathrm{N}=360$} & MCA184 (51.1\%) & $15(4.2 \%)$ & Y353 (98.1\%) & $16(4.4 \%)$ \\
\hline & Acom 77 (21.4\%) & & T7 (1.9\%) & \\
\hline & BA-tip 80 (22.2\%) & & & \\
\hline & IC-PC 1 (0.3\%) & & & \\
\hline & IC-tip17 (4.7\%) & & & \\
\hline & ACA1 (0.3\%) & & & \\
\hline
\end{tabular}

thrombotic complications occurred frequently in small vessels such as the Acom. Therefore, the effect of narrowing the lumen due to crossing of stents is considered to become notable when the diameter of the parent artery is small, and the T-stenting technique is an option worth consideration.

Stenting was unsuccessful in $4.2 \%{ }^{3,4,7-12)}$ While no unsuccessful stenting was observed in the seven patients treated using the T-stenting technique, ${ }^{3,4)}$ stenting is not expected to be easy as slight malposition may lead to failure. Since malposition to the proximal side results in Y-stenting, and since stenting may be useless if it is positioned widely to the distal side, stenting should be performed by a skilled physician. We adjusted the position of the stent by expecting the degree of shortening from the diameter of the vessel to be stented and deploying the stent at a position where the proximal marker slightly overlaps with the first stent. In so doing, we carefully manipulated the microcatheter not to allow the stent to migrate distally. In our patients, the second catheter could be placed with its proximal end in contact with the first stent.
In the cases presented here, the lesions were a bifurcation type in Case 1 and a side-wall type in the Case 2. In bifurcation type lesions, the proximal end of the second stent may fall into the aneurysm if the branching angle is sharp. It is considered important to place the first stent from the artery with a sharper angle to the parent artery and the second stent in the artery easier to stent. Also, if both arteries are sharply bifurcated and considered to be dangerous to stent, the Y-stenting technique should be considered as an option. In large side-wall type aneurysms, such as those with a branch springing from the dome, the proximal end of the stent may become free and unstable in the aneurysm. In our patients, satisfactory results could be obtained by using a relatively long stent, firmly fixing its distal end, and avoiding overdense embolization near the proximal end. However, if the diameter of the branched artery is relatively large, and the risk of thrombotic complications is judged to be low, the Y-stenting technique, by which the proximal end of the second stent is more stable, should be considered. 
Concerning the stent types, there is a report that an opencell stent, which shows better apposition to the vessel wall, should be considered as the first stent to prevent stent migration. ${ }^{14)}$ However, as we considered that the risk of stent migration due to interference between stents was low by the T-stenting technique, we used Enterprise VRD, which is a closed-cell stent, in expectation of the recurrence-preventing effect due to a decrease in the inflow of blood into the aneurysm and flow diversion associated with straightening of the vessel. ${ }^{15)}$ When the two patients reported here were treated, the laser-cut stent was the only neck-bridge stent available in Japan, but with future propagation of braided stents, the options of stents that can be used for the dual stenting technique are expected to increase, possibly leading to improvements in the therapeutic results.

The administration of antiplatelet drugs from before the procedure and the intra-procedural use of heparin are also considered to be closely related to ischemic complications. In many reports of the stent assist technique, dual antiplatelet therapy with aspirin and clopidogrel was performed with a target activated clotting time (ACT) of $250 \mathrm{~s}-300$ s. ${ }^{3,4)}$ At our hospital, when the stent assist technique is employed, the patients are heparinized similarly with a target ACT of $250 \mathrm{~s}-300 \mathrm{~s}$, triple antiplatelet therapy with aspirin, clopidogrel, and cilostazol is initiated from 5 days before the procedure, and, if there are no problematic clinical symptoms or imaging findings, the administration of clopidogrel and cilostazol is continued by discontinuing aspirin about 1 week after the procedure. In the two cases presented here, the dual antiplatelet therapy is continued, and the timing of reducing the number of drugs to one or discontinuing the antiplatelet therapy will be decided according to the patient background, imaging findings, and diameter of the parent artery similarly to simple stenting. Neither of the patients has developed thrombotic complications to the present. Recently, the measurement of platelet responses using devices such as VerifyNow has been reported to be useful for checking the responsiveness to antiplatelet drugs. ${ }^{16)}$ Particularly, in patients treated by the dual stenting technique, platelet aggregation is recommended to be monitored to reduce thrombotic complications.

\section{Conclusion}

Two cases of intra-aneurysmal coil embolization using the T-stenting technique are presented. This procedure may reduce thrombotic complications compared with the overlapping Y-configuration stenting technique, and further accumulation of cases is necessary.

\section{Disclosure Statement}

The first author has completed COI self-registration in the NPO Japanese Society for Neuroendovascular Therapy. There are no COI to disclose concerning this paper.

\section{References}

1) Lessne ML, Shah P, Alexander MJ, et al: Thromboembolic complications after neuroform stent-assisted treatment of cerebral aneurysms: the duke cerebrovascular center experience in 235 patients with 274 stents. Neurosurgery 2011; 69: 369-375.

2) Fargen KM, Hoh BL, Welch BG, et al: Long-term results of enterprise stent-assisted coiling of cerebral aneurysms. Neurosurgery 2012; 71: 239-244; discussion 244.

3) Cho YD, Park SW, Lee JY, et al: Nonoverlapping Y-configuration stenting technique with dual closed-cell stents in wide-neck basilar tip aneurysms. Neurosurgery 2012; 70: 244-249.

4) Yavuz K, Geyik S, Cekirge S, et al: Double stent-assisted coil embolization treatment for bifurcation aneurysms: immediate treatment results and long-term angiographic outcome. AJNR Am J Neuroradiol 2013; 34: 1778-1784.

5) Chow MM, Woo HH, Masaryk TJ, et al: A novel endovascular treatment of a wide-necked basilar apex aneurysm by using a Y-configuration, double-stent technique. AJNR Am J Neuroradiol 2004; 25: 509-512.

6) Jankowitz BT, Thomas A, Jovin T, et al: Y stenting using kissing stents for the treatment of bifurcation aneurysms. J Neurointerv Surg 2012; 4: 16-21.

7) Thorell WE, Chow MM, Woo HH, et al: Y-configured dual intracranial stent-assisted coil embolization for the treatment of wide-necked basilar tip aneurysms. Neurosurgery 2005; 56 : 1035-1040; discussion 1035-1040.

8) Lozen A, Manjila S, Rhiew R, et al: Y-stent-assisted coil embolization for the management of unruptured cerebral aneurysms: report of six cases. Acta Neurochir (Wien) 2009; 151: 1663-1672.

9) Lee WJ, Cho CS: Y-stenting endovascular treatment for ruptured intracranial aneurysms: a single-institution experience in Korea. J Korean Neurosurg Soc 2012; 52: 187-192.

10) Zhao KJ, Yang PF, Huang QH, et al: Y-configuration stent placement (crossing and kissing) for endovascular treatment of wide-neck cerebral aneurysms located at 4 different bifurcation sites. AJNR Am J Neuroradiol 2012; 33: 1310-1316.

11) Akgul E, Balli T, Aksungur EH: Hybrid, Y-configured, dual stent-assisted coil embolization in the treatment of wide-necked bifurcation aneurysms. Interv Neuroradiol 2015; 21: 29-39.

12) Bartolini B, Blanc R, Pistocchi S, et al: "Y" and " $X$ " stentassisted coiling of complex and wide-neck intracranial bifurcation aneurysms. AJNR Am J Neuroradiol 2014; 35: 2153-2158. 
13) Johnson AK, Munich SA, Tan LA, et al: Complication analysis in nitinol stent-assisted embolization of 486 intracranial aneurysms. J Neurosurg 2015; 123: 453-459.

14) Akgul E, Aksungur E, Balli T, et al: Y-stent-assisted coil embolization of wide-neck intracranial aneurysms. A single center experience. Interv Neuroradiol 2011; 17: 36-48.
15) Kono K, Terada T. Hemodynamics of 8 different configurations of stenting for bifurcation aneurysms. AJNR Am J Neuroradiol 2013; 34: 1980-1986.

16) Fifi JT, Brockington C, Narang J, et al: Clopidogrel resistance is associated with thromboembolic complications in patients undergoing neurovascular stenting. AJNR Am J Neuroradiol 2013; 34: 716-720. 